\title{
Monitoring environment, health and perception. An experimental survey on health and environment in Flanders, Belgium
}

\section{Hans Keune* and Ilse Loots}

Department of Sociology,

Faculty of Political and Social Sciences,

University of Antwerp,

Sint Jacobstraat 2,

B-2000 Antwerpen, Belgium

Fax: +32 32204901

E-mail: hans.keune@ua.ac.be

*Corresponding author

\section{Liesbeth Bruckers}

Center for Statistics,

University Hasselt,

Agoralaan 1, Building D,

B-3590 Diepenbeek, Belgium

\section{Maaike Bilau}

Department of Public Health, Ghent University Belgium,

University Hospital, 2 Blok A, De Pintelaan 185, B-9000 Ghent, Belgium

\section{Gudrun Koppen}

Environmental Toxicology - Environment and Health, Flemish Institute of Technological Research (VITO),

Boeretang 200, B-2400 MOL, Belgium

\section{Nik Van Larebeke}

Study Centre for Carcinogenesis and

Primary Prevention of Cancer,

Department of Radiotherapy,

Nuclear Medicine and Experimental Oncology,

University of Ghent-Belgium,

Universitair Ziekenhuis 3K3,

De Pintelaan 185, B-9000 Gent, Belgium 


\title{
Greet Schoeters
}

Environmental Toxicology - Environment and Health, Flemish Institute of Technological Research (VITO), Boeretang 200, B-2400 MOL, Belgium

\section{Vera Nelen}

Provincial Institute for Hygiene,

Kronenburgstraat 45, B-2000 Antwerp, Belgium

\section{Willy Baeyens}

Department of Analytical and Environmental Chemistry, VUB (Free University of Brussels), Pleinlaan 2, B-1050, Brussels, Belgium

\begin{abstract}
The Centre of Expertise for Health and Environment started a biomonitoring campaign at the end of 2001, in Flanders (Belgium). The main purpose of this project, funded by the Flemish government, is to investigate the relationship between environmental pollution and human health. This is done by measuring pollutants and health effects in human beings. Social scientists cooperating with the environmental and health experts proposed to include a questionnaire on risk perception related to environment and health. Taking into account, risk perception is important with regard to risk communication, risk assessment and the management of complex issues such as health and environment. We present the results of our survey of 1,165 mothers of newborn babies, who participated in the first campaign of the biomonitoring. The perception research discussed in this paper can be evaluated as a successful experiment, with potential for further development and use.
\end{abstract}

Keywords: biomonitoring; interdisciplinarity; knowledge integration; participation; risk communication; risk perception; survey; transdisciplinarity; trust.

Reference to this paper should be made as follows: Keune, H., Loots, I., Bruckers L., Bilau M., Koppen G., Van Larebeke, N., Schoeters, G., Nelen V. and Baeyens, W. (2008) 'Monitoring environment, health and perception. An experimental survey on health and environment in Flanders, Belgium', Int. J. Global Environmental Issues, Vol. 8, Nos. 1/2, pp.90-111.

Biographical notes: Hans Keune is a Political Scientist working at the Faculty of Political and Social Sciences, University of Antwerp, Belgium. His main research activities are part of the work of the Centre of Expertise for Health and Environment in Flanders (Belgium). His current research focuses on risk perception, risk communication, knowledge integration, interdisciplinarity, transdisciplinarity, participation and boundary work science - government society.

Ilse Loots is a Professor at the Faculty of Political and Social Sciences, University of Antwerp, Belgium. She received her $\mathrm{PhD}$ in urbanity and settlement patterns of activities in urban tissue from the University of Antwerp, Belgium. Her current research focuses on: (the strategic renewal of) 
environmental policy, risk communication and spatial planning. Part of her work concerns the Centre of Expertise for Health and Environment in Flanders (Belgium).

Liesbeth Bruckers is a Researcher at the Hasselt University. She received the BS degree in Physics (1995) from the University of Antwerp and the Master of Science in Biostatistics degree (1996). She is responsible for the planning and administrative follow-up of the Centre of Statistics's in - and out house statistical consultancy. Her research interests closely relate to the consultancy projects. She actively participated in: survey methodology, psychiatric epidemiology, epidemiological and clinical studies. She taught short introductory courses in Biostatistics and is involved in the Applied Statistics programme.

Maaike Bilau is a Biologist, working at the Department of Public Health, Ghent University, since 2001. Her PhD research is situated in food safety problems, such as exposure and risk assessments of chemical contaminants via food, evaluated in a public health perspective. She is responsible for the development and evaluation of the food frequency questionnaires in the biomonitoring programme of the Centre of Expertise for Health and Environment in Flanders (Belgium).

Gudrun Koppen is an Engineer in Chemistry and Agricultural Sciences (University of Ghent, 1993). Since 1999, she is working in the field of Human and Health monitoring programmes at the Environmental Toxicology department of Vito. Tasks involved are mainly development of study protocols and questionnaires, organisation of laboratory analyses, general logistical organisation and (statistical) analysis/interpretation of the data.

Nik Van Larebeke is a Medical Doctor (University of Ghent, 1972) who obtained a PhD in 1977 (University of Ghent) on the induction of plant tumours by Agrobacterium tumefaciens. In 1978, he founded a genotoxicity laboratorium in the Pasteur Institute in Brussels. Between 1984 and 1994, he worked on cell motility and invasion. Since 1994, he is mainly active in cancer prevention and human biomonitoring.

Greet Schoeters is a Research Manager of the Unit of Environmental Toxicology of VITO (Flemish Institute for Technological Research) and Professor at the Faculty of Pharmaceutical, Biomedical and Veterinary Sciences. Her research activities focus on human biomonitoring and biomarker development which are applied for hazard identification and risk assessment of environmental chemicals.

Vera Nelen is a Head of the Department of Public Health in the Provincial Institute for Hygiene of the province of Antwerp, Belgium. She is involved in programmes on health and environment since 1989 and in the biomonitoring programmes in the Flanders region since 1999. Task in the biomonitoring programmes is the organisation of the fieldwork for the recruitment of participants.

Willy Baeyens is a Professor at the Faculty of Sciences (Vrije Universiteit Brussel). He obtained his PhD in 1977 at the same university on a numerical dispersion model of mercury compounds in the Scheldt Estuary. Since then, he is working on environmental issues especially pollution and its impact on the ecosystem and human health. He is actually the coordinator of the Centre of Expertise for Health and Environment in Flanders (Belgium). 


\section{Introduction}

\subsection{Biomonitoring}

In Flanders (Dutch speaking part of Belgium) a biomonitoring campaign was started at the end of 2001. For this project, a Centre of Expertise for Environment and Health (http://www.milieu-en-gezondheid.be/) was funded by the Flemish government, for a period of five years. Within this Centre, researchers from all Flemish universities and two research institutes provide different sorts of expertises: from medical-environmental to social scientific experts.

The main purpose of the biomonitoring project is to investigate the very complex relationship between environmental pollution and human health. This is done by measuring some selected pollutants and certain health effects in human beings. The focus lies on three different target groups: newborn babies, adolescents and adults. Each campaign is carried out in eight areas of Flanders. These areas have different environmental characteristics, such as industrialised, rural (the countryside), urbanised, near waste incinerators and near fruit orchards. Part of the objective of this biomonitoring is to focus on a comparison of exposure and health effects associated with these different types of environmental situations. The study was approved by the ethical commission of the University of Antwerp and by the privacy commission. In this paper, we focus on the first wave, new born babies, of which the campaign is finished at this stage. Over 1,100 mothers of newborn babies participated in the perception research.

\subsection{Co-variables}

To measure the exposure and health effects in human beings, biomarkers are used. Exposure markers measure the amount of chemicals present in tissue fluids such as blood. Markers for effect measure the possible biological and health impacts of these exposures. Apart from the environment other factors may influence these markers, such as lifestyle, health status, working conditions and food intake. If we want to investigate the contribution of environmental exposure to the biomarkers, we need to correct for the contribution of other factors, the confounding factors and co-variables. Many of these covariables are quantified through questionnaires. Social scientists within the Centre of Expertise for Environment and Health suggested using this opportunity to add a short questionnaire on perception with regard to environmental risks for human health. In the first campaign, 1,160 mothers of newborn babies completed this questionnaire on risk perception (Keune et al., 2005).

\subsection{Outline of the paper}

Firstly, we describe the aim of our research on risk perception and how the questionnaire was designed. We highlight some opportunities for perception research, but also shed some light on the limitations. We will also shortly present insights from literature on risk perception.

Next, the results of the questionnaire are discussed. If relevant, these results are also compared with the results of the biomonitoring. Furthermore, we compare them with results from Eurobarometer research on environment and on health. Finally, we discuss 
and evaluate our research and approach. We also briefly introduce some options for further use of the research results in the future.

\subsection{Risk perception}

Public health risks related to environmental pollution are scientifically very complex. This is not the only reason why environmental policymaking is difficult. Apart from the lack of unambiguous scientific knowledge, risks are socially complex: they are interwoven with our way of life, with our norms and values. Different perceptions of risk are related to many factors. Next to scientific factors, also social factors are very influential (Covello, 1991; Slovic, 1998; Renn and Rohrmann, 2000), e.g. whether people are voluntarily exposed to risks, and the distribution of costs and benefits of riskgenerating activities such as industry. Next to this, the amount of trust people have in individuals or organisations that are responsible for risk management is of great importance (Renn and Levine, 1991; Wynne, 1996). Wynne (1992) also stresses that risk perception is not purely an individual matter. It is part of and shaped by the interaction between people.

When Wynne (1992) discusses risk perceptions as part of a social process, he refers to the concept of social learning. In discussion with other people, the ideas and values that are of importance to the perception of risks are exchanged and tested. People learn from other people's viewpoints. Such a process of social learning can also be understood as negotiation. In discussion between different viewpoints, the problem definition, the meaning or a problem solution strategy can be constructed by mutual learning and negotiating.

Risk perceptions can also be complex because of apparent paradoxes. In a consultation of residents in a neighbourhood next to a heavily polluting factory for example, there seemed to be little unrest about the health risks (Keune et al., 2002; Keune, 2003). Further research showed that lack of individual opportunities to change the problematic situation, or for residents to move to another residential area, caused people to be more or less resigned to their fate.

\subsection{Why research on risk perception?}

Risk perception research is useful for several reasons. One obvious reason is that purely technical or quantitative research methods cannot explain why people perceive risks as they do: technical or quantitative research methods are limited because of blind spots. Moreover, understanding risk perception is valuable for risk management (Renn and Rohrmann, 2000). An important tool in risk management, risk communication, needs to take into account risk perception. In order to tackle complex problems such as environmental health problems, it is necessary to incorporate different forms of knowledge of these problems as well as respect the fact that professionals and nonprofessionals, for example, may perceive problems quite differently.

One of the main problems in risk communication is negligence of the fact that different perceptions are relevant and should be respected. Overcoming the gap between science and the public is still one of the biggest challenges of risk communication. Mutual understanding is necessary to create trust in order to solve problems that are both scientifically and socially complex. Risk communication is no panacea though, but will result in fewer misunderstandings and 'better' (informed) conflicts (Drijver and 
Woudenberg, 1999). Moreover, from the perspective of perception management, in order to achieve social change, taking perceptions seriously is a prerequisite. Finally, an important reason for taking into account lay knowledge is simply the fact that science itself suffers from many uncertainties and unknowns. Lay knowledge may contribute to the better understanding of problems. A social scientific perspective on risks thus broadens the horizon and offers other ways of understanding and describing reality and the way people socially construct their own realities (Renn and Rohrmann, 2000).

\subsection{Research objectives}

The first objective of our research was to investigate the perceptions of participants in the biomonitoring study in relation to environment and health issues. This objective was subdivided in three sub-objectives:

Do respondents think that environmental problems exist in their neighbourhood? And do they think these problems create health risks?

- To what extent do respondents trust actors involved with environmental problems?

- How should policies with regard to these problems be arranged in their opinion?

A second objective of our research was to investigate to what extent perception research is of value to biomonitoring research.

\subsection{Practical and thematic opportunities}

The idea to combine perception research with biomonitoring mainly resulted from cooperation between social scientists and the environmental and health experts. The opportunity of linking perception research with questionnaires to several thousands of participants (in three campaigns over 4,000 people) combined with the interest of investigating public perceptions of environment and health issues formed the basis. Moreover, the fact that the biomonitoring is likely to be repeated after several years, offers the possibility of monitoring perceptions over time.

The opportunity to work on integration of different perspectives and forms of expertise, different scientific disciplines and lay knowledge and perceptions, is of great importance for bridging the gap between science and society. Of course, this is a step-bystep process. We cannot expect things to change overnight. It is a rather complex process: different spheres with different vocabularies cannot be expected to 'understand' each other easily. Moreover, some division of labour will of course remain. It does not mean that the scientific specialised expertise is no longer needed. On the contrary, the complexity of the issues at hand necessitates a combined effort. Based on this research, we hope to come up with some indications and hypotheses for further work and research on both perceptions and integration of different perspectives. In Section 4, we will come back to this. 


\section{Method}

\subsection{Participants}

We had to adapt to the recruitment of participants of the biomonitoring. This meant that only a select group of respondents could be questioned during each campaign: in this case, mothers of new born babies recruited in eight areas in Flanders. Geographically, these regions cover some $20.0 \%$ of the total region $(22.0 \%$ of the surface in Flanders, $20.0 \%$ of total population, and $21.0 \%$ of the total number of Flemish municipalities). Within these areas, we depended upon the cooperation of a (random) selection of maternity hospitals. All selected maternities were willing to participate. Also participants had to fulfil certain criteria in order to enrol in the study. Mothers had to give written informed consent; they had to be residents of the area for at least five years prior to the study. In addition, they should be able to fill in a Dutch questionnaire. No statistically representative sample of the Flemish population as such was therefore possible. The fact that in the two next campaigns, two different age groups, adolescents and older people, will be monitored will compensate for this limitation to some extent.

The number of participants in each campaign was attuned to the analytical needs of the biomonitoring. In each campaign, 200 participants are aimed for each of the eight areas, in total 1,600 participants in each of the three campaigns. Thousand hundred and ninety-five mothers of newborn babies participated in this biomonitoring campaign. Only 35 did not fill out the risk perception questionnaire. The target number of 200 participants per study area for the biomonitoring was not reached in every study area; specifically near municipal waste incinerators and in the Albertkanaal zone, these numbers have not been reached. For the perception research: see Table 1.

Table 1 Number of participants in the study areas

\begin{tabular}{lr}
\hline Study areas & Number \\
\hline Urban Agglomeration of Antwerp & 206 \\
Urban Agglomeration of Ghent $^{\mathrm{a}}$ & 186 \\
Ports (Industrial zones) $^{\mathrm{a}}$ & 156 \\
Albertkanaal Chemical industry zone & 62 \\
Vicinity of Non-Ferro plant in Olen $_{\text {Areas with fruit orchards }}$ & 125 \\
Rural areas & 199 \\
Vicinity of municipal waste incinerators (Menen and elsewhere & \\
Total & 202 \\
\hline
\end{tabular}

Notes: ${ }^{\mathrm{a}}$ Antwerp (Chemical) and Ghent (Steel). ${ }^{\mathrm{b}}$ As 14 of the 24 participants from these areas came from the municipality of Menen, our observations cannot be considered representative of areas around Flemish municipal waste incinerators in general. This area will be referred to as Menen +.

Seventy-five percent of the mothers were between the ages of 25 and 35, and the highest level of education of most mothers was higher secondary education, both technical and general (see Table 2). 
Table 2 Educational level of the participants

\begin{tabular}{lc}
\hline Highest level of education mother & Percentage \\
\hline Primary school & 1.5 \\
Lower secondary technical education & 7.3 \\
Lower general secondary education & 2.5 \\
Higher secondary technical education & 30.7 \\
Higher secondary general education & 34.0 \\
Higher non-university & 7.5 \\
University & 14.0 \\
Other & 1.2 \\
Missing & 1.4 \\
Total & 100.0 \\
\hline
\end{tabular}

\subsection{Questionnaire}

The large size of the questionnaires needed for interpretation of biomonitoring results (personal characteristics, environment and health related topics, lifestyle and food habits) forced us to attach a very limited number of questions focussing on risk perception. Explaining a complex issue such as risk perception in a few questions is very difficult. The same goes for topics such as environment and health. Therefore, we had to limit the scope of the questionnaire. The fact that the perception research on the combination of environment and health is rather new in Flanders also means that the research is rather experimental in character. Furthermore, the use of a written survey method has several well-known limitations.

Even though a very complex issue such as risk perception neither thoroughly nor fully understood by means of a survey (see for example, Wynne, 1992), we opted for this opportunity because it still may contribute, together with other forms of perception research, to better understanding and better risk communication and management. Furthermore, involving perception research directly with environmental and health research may contribute to overcoming the big gap between science and society. Both pragmatic and experimental reasons for this perception research thus influenced our choices.

The questionnaire consisted of closed and open-ended questions. Both have advantages and disadvantages. Partly this choice was made because of a practical reason: using (some) closed questions would make the process of analysing data easier. Of course sufficient knowledge about the options respondents may choose should be present. In order to include 'missed' options, each closed question that offered a wider variety of options had at least one open category for respondents to add other options.

For issues where we considered it would be more appropriate to focus on the vocabulary of the respondents and try not to steer the answers too much, we used openended questions. These concerned mainly issues where we believed the explorative nature of the questionnaire to be more important than the aim to achieve statistically reliable outcomes. 


\subsection{Issues}

We selected a wide variety of relevant issues for our research at the beginning of the project. Because of the practical limitations, we needed to restrict to the following selection of issues (see Table 3).

Table 3 Relevant research issues in the questionnaire

Issues in the questionnaire

Are there environmental problems in the neighbourhood you live in?

And if so, do these problems have an impact on the health of household members?

Which actors do you trust with regard to information on environmental problems? And which actors should inform you? And what are the actors you have experience with?

Which actors are considered as mainly responsible for solution of environmental problems

How should local residents be involved with regard to policymaking on environment and health? Do you yourself want to be involved?

Do you want to take part in further risk perception research?

Environmental policymaking: what should be improved?

Specific environmental problems and health effects were addressed with open-ended questions. In addition to the last issue, environmental policymaking, was examined using an open-ended question. The other issues were examined mainly using closed questions with a limited choice of options. Ranking of the environmental issue amongst other given key problems or worries (such as world peace, employment and poverty) was avoided, seen the regional and local focus in the inquiry.

\subsection{Analysis}

The answers to the closed questions were scanned and statistically analysed with Statistical Package for the Social Sciences (SPSS). The answers to the open-ended questions or categories were coded and entered in the database by hand. Statistical analysis was only done where a number of respondents were sufficient. Where numbers were insufficient for statistical analysis, we used descriptive analysis.

The biggest challenge with regard to the analysis of the open-ended questions concerned the specific environmental problems. To illustrate our analysis, we give two examples:

1 lead and cadmium pollution by industrial factory A and

2 heavy metals in the soil caused by industry.

In both the examples, heavy metals are mentioned. The first respondent labels the specific metals and attributes the specific name of the actor causing the problems: industrial factory A. The second respondent names the place where the pollution is to be found and generalises the cause to 'industry'. This can be unravelled and sorted in the following manner (Table 4): 
Table 4 Example analysis of open-ended questions

\begin{tabular}{llc}
\hline Main category & & Sub categories \\
\hline Polluter $\rightarrow$ & Industry $\rightarrow$ & Factory A \\
Pollutant $\rightarrow$ & Heavy metals $\rightarrow$ & Lead \\
& & Cadmium \\
Location of pollution $\rightarrow$ & Soil & - \\
\hline
\end{tabular}

The main questions we tried to answer in our research were the following (Table 5):

Table 5 Analytical focus points for the questionnaire

1 How do respondents score on the closed questions?

2 What diversity of answers can be found in open-ended questions?

3 How do respondents score on the open-ended questions?

4 Do answers to questions differ per geographic research area?

5 Can we explain these differences based on geographical differences?

6 Can we find other variables (e.g. age or educational level) that explain geographical differences in perceptions?

The fourth analytical question fits with one of the central research questions of the biomonitoring: can divergent monitoring results be explained by differences between the different areas, each representing different types of environmental situations?

\section{Results}

\subsection{Response rate}

The response to the questionnaire was high: over $97.0 \%$ of the mothers participating in the biomonitoring completed the perception questionnaire. Most individual questions also had high response rates.

\subsection{Local environmental problems}

Of the mothers $57.2 \%$ indicated no environmental problems in their residential areas (6.3\% missing). Of the mothers that do indicate an environmental problem (36.5\%), most reside in areas with industrial activities or in urban agglomerations (see Figure 1). A lower percentage of respondents in areas with fruit orchards and in rural areas generally, indicated environmental problems; not very surprising, since the countryside has the image of being relatively less problematic with regard to the environment. When we compare this with the outcome of the biomonitoring (http://www.milieu-engezondheid.be/), we notice a strikingly different picture. The biomonitoring indicated that, in several rural areas, levels of persistent chlorinated compounds such as dioxin-like compounds and Polychlorinated Biphenyls (PCBs), were relatively high compared to the industrial zones of Olen and Albertkanaal, near ports, and the urban agglomeration of Ghent. 
Figure 1 Presence of local environmental problems in study areas

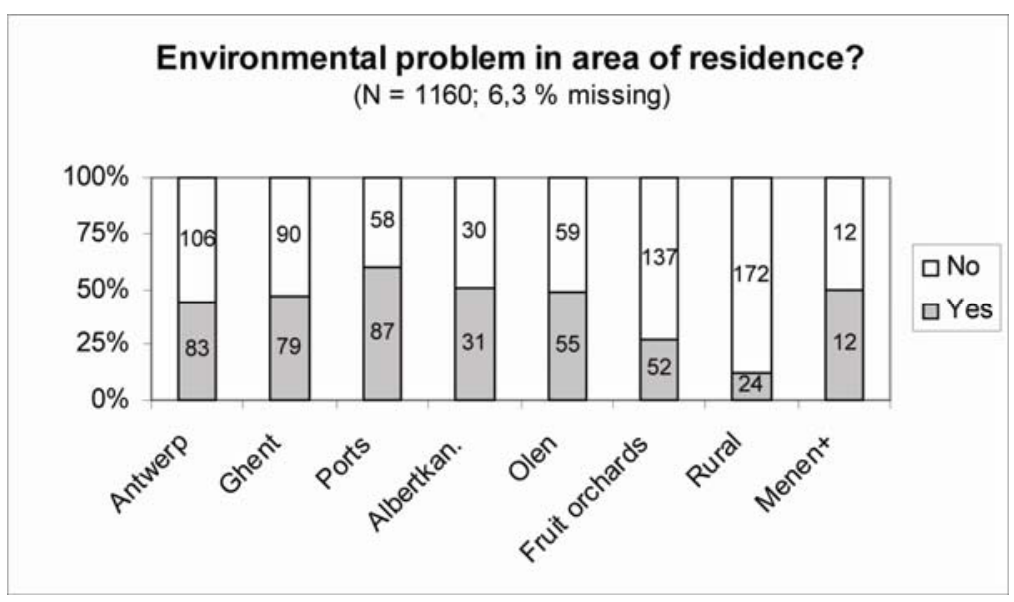

The differences between regions in the proportion of mothers indicating an environmental problem are statistically significant $(p<0.0001){ }^{1}$ The differences between age groups and levels of education in the proportion of mothers indicating an environmental problem are also statistically significant (respectively, $p=0.003$ and $p<0.0001$ ). The data clearly show (Figure 2) a positive relationship between age and the number of mothers that indicates an environmental problem. The same is true for the highest level of education: mothers with a higher educational level more often indicated environmental problems. Logistic regression analysis showed that the differences in perceptions of environmental problems between areas remain statistically significant, even after correcting for effects of age and educational level. The correlation between study area and perception of environmental problems thus remains statistically significant $\left(R^{2}=0.194\right)$.

Figure 2 Presence of local environmental problems according to different age groups

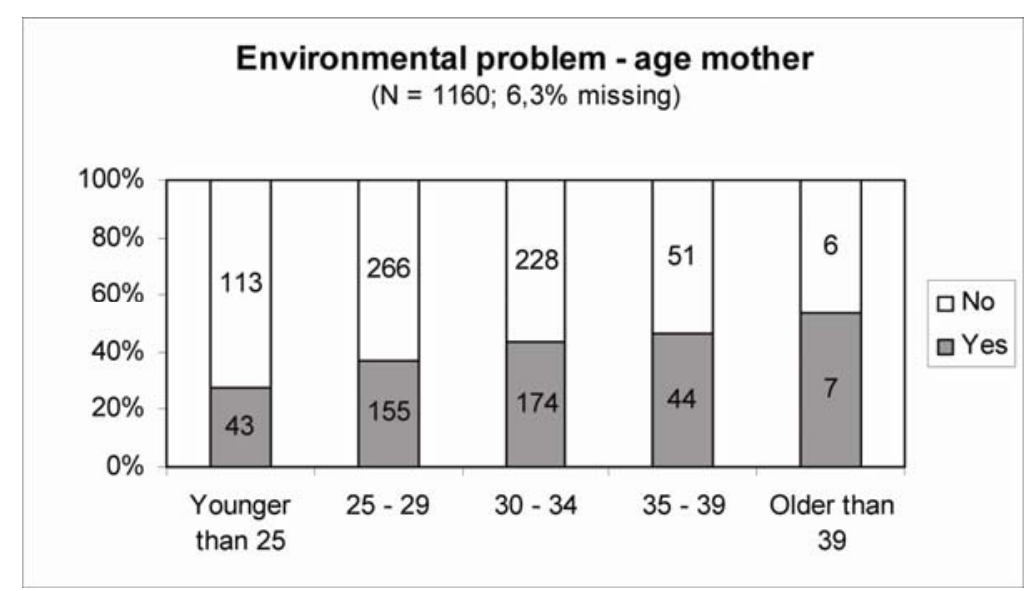


On the basis of these results, we cannot explain the relatively large proportion of mothers who did not articulate environmental problems. Nor can we explain the differences because of age and educational level although we know that environmental consciousness is, generally spoken, linked up to higher education and welfare (and socialisation on its turn). This relation also counts for the Flemish population in general (Ackaert and Swyngedouw, 1998). Further research may provide indications that are more precise. It may be helpful to formulate some further research questions and think about possible explanations.

One possible explanation could be that some people do not indicate environmental problems because of what may be called 'coping behaviour'. As in the case of the residents living next to a polluting factory (Keune et al., 2002; Keune, 2003), some respondents may ignore the issue for more or less similar reasons, such as lack of opportunities to change the situation, or lack of trust in risk management. Furthermore, some respondents may consider themselves economically dependent upon, e.g. industrial activities that cause problems (see for example, Wynne, 1996). In addition, respondents may relate environmental problems to 'their (Western) way of living', a way of living they do not intend to give up: therefore, a strategic response may be the consequence.

We cannot exclude the possibility of misinterpretation of the questions in the questionnaires. Perhaps some respondents understood the word 'environment' differently to how the researchers understood it (see also Weale, 2000 for comparable difficulties with the Eurobarometer). Perhaps this explains partly the influence of educational level: more of the respondents with higher levels of education probably share the vocabulary of researchers who also have a higher educational level. Possibly lack of, or different kinds of, information about environmental conditions may also be of influence here: perhaps those with higher educational levels have more or different information about the environment.

Of the mothers that indicated an environmental problem (36.9\% of all respondents), most of them indicated that they worried about the health consequences of these environmental problems (78.0\%). Moreover, most of these mothers articulated specific environmental problems (99.8\%). The main categories we distinguished for these issues were environmental compartment (soil, air and water) and types of nuisance (smell, sound and light), pollutants and polluter. Because of the open nature of our approach to this issue, statistical relevance is relatively poor, as we indicated earlier in this paper: 212 respondents named an environmental compartment; 164, a pollutant and 379, a polluter. The main environmental problems indicated by the respondents are air pollution and emissions from traffic. The main polluters that were mentioned are companies. When we examine differences between study areas, we must highlight that statistical interpretations are not appropriate because of small numbers. Therefore, these results need to be analysed with care and can only lead to suggestions for further research. Some interesting differences show up between the study areas with regard to the sources of pollution. In most areas, companies were mentioned most often as polluters. However, in the urban agglomeration and in rural areas, traffic and, to a lesser extent, private polluters also scored relatively high as local environmental problems.

To what extend does the perception of environmental problems coincide with 'reality' one may ask. With regard to the negative impact of traffic on the environment, this certainly coincides with the findings of Flemish environmental research (Van Steertegem, 2005). With regard to the impact of companies conclusions cannot be drawn unambiguously (ibid.). First of all, a lot of smaller companies still contribute significantly 
to environmental pollution. Secondly, some of the bigger companies score relatively better on environmental performance. This does not mean that their contribution to environmental pollution is not substantial. Thirdly, some of the bigger companies still discharge vast amounts of pollutants. The contribution of households to environmental pollution seems to be underestimated when we look at perceptions: especially incineration of household waste at home is problematic (ibid.). According to experts, overall companies certainly contribute substantially to environmental pollution. Nevertheless, experts indicate that the contribution of traffic to pollution is bigger (ibid.).

\subsection{Health effects}

Only a small number of mothers who indicated environmental problems also indicated health effects caused by these problems either on themselves or on other members of their household (66 respondents out of 423). This means that only a small number of the respondents who indicated both environmental problems and concern with regard to health effects actually indicated health problems related to these environmental problems. Paradoxical as this may seem, this might not be that surprising when we take into account the very complex relation between health and environment: health effects are difficult to link directly to purely environmental factors, and may only become obvious in the long run, for example in the case of cancer. Possibly, we should link concern more to the issue of risk. The fact that respondents do not see health effects at a certain moment in time does not mean that they do not worry about the risk of becoming ill.

Most respondents who indicate the existence of environment-related health problems articulated specific health effects (60 out of 66). About half of the health problems that were indicated concern respiratory problems. This seems to be consistent with the indication of air pollution as one of the main environmental problems. Other effects mentioned included allergies, Chronic Fatigue Syndrome, eczema, headaches, ear problems and stress.

\subsection{Trust, participation and policy}

Issues with regard to environment and health rank high on the political agenda. Half of the questions of the questionnaire were related to policymaking. One of the main issues is trust in actors involved in risk communication and management. Another important issue is the involvement of the public in policy and decision-making.

\subsection{Trust}

Trust is a very complex issue, difficult to grasp in a short questionnaire. Therefore, we do not pretend to have captured this topic fully. We investigated one aspect of trust by asking respondents how much they trust several (pre-given) actors that may function as sources of information on local environmental problems (in principle respondents had to score every source on a scale from little to moderate to high trust). The list of actors was composed based on experience within the field of local and environmental policymaking and communication media. The fact that the category 'other' was hardly used shows that the pre-given list of actors was rather exhaustive (Figure 3): 
Figure 3 Trust in information sources on environmental problems

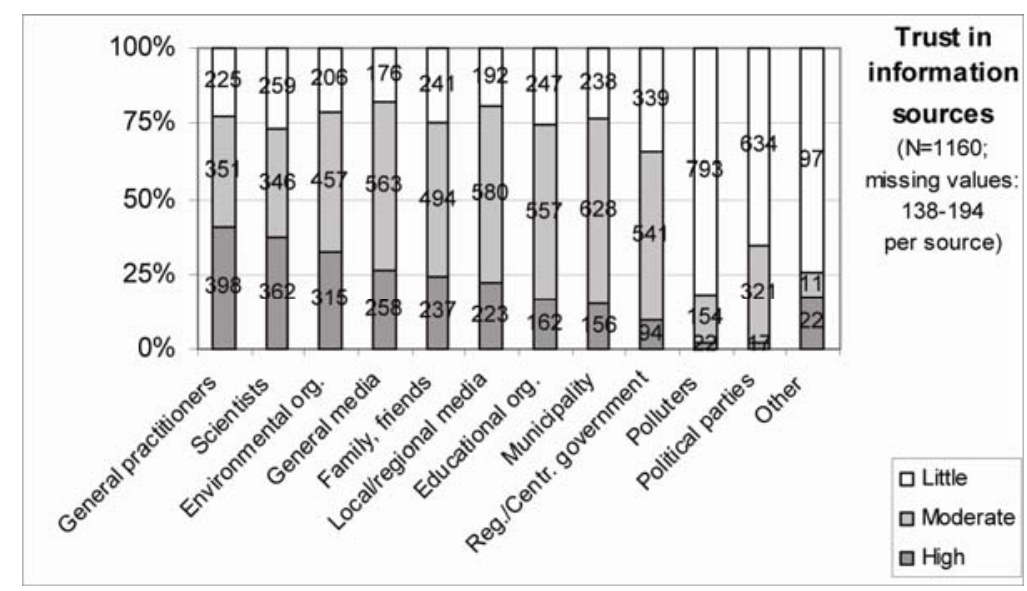

The results of this survey regarding perception bear a striking resemblance to those of a recent Eurobarometer poll (European Commission, 2005). First, we notice the very negative perception of polluters. This is rather similar to the lack of trust we find in this Eurobarometer poll ${ }^{2}$ with regard to companies. Companies also appear to be the main cause for environmental problems according to the respondents in our study. Another similarity is the amount of trust in scientists, who score relatively high in both this Eurobarometer poll and in our research. Also rather comparable is the overall moderate trust in governmental authorities, local, regional and central. We see the same moderate trust with regard to the media in our research. The Eurobarometer poll differentiates between different forms of media, such as television, newspapers and radio. This makes it difficult to compare.

In this Eurobarometer poll, environmental organisations score clearly highest. In our research, however, their score is rather moderate. Both scientists and general practitioners (not part of the Eurobarometer research) score well in our research. In addition, actors such as educational organisations and family and friends score relatively better in our research than in this Eurobarometer poll. Political parties, second of the least trusted actors in our research, were not part of this Eurobarometer research, except for the green parties.

Statistical analysis on possible correlations between trust and respondents' characteristics was only possible with regard to individual types of actors as source of information on local environmental problems. We found a statistically significant positive correlation between trust and educational level with regard to the municipality $(p=0.048)$, regional and central government $(p=0.002)$, scientists $(p<0.0001)$, and environmental organisations ( $p=0.019$ ): a higher educational level is related to a higher trust with regard to these actors. We found a statistically significant negative correlation on trust and age, but only with regard to two actors: general media $(p=0.014)$ and political parties $(p=0.015)$.

We also asked respondents who they think are necessary sources of information with regard to environmental problems. We see little correlation here with the issue of trust. Actors that scored relatively moderate on trust, in particular governmental authorities, followed by the media, and environmental organisations, were expected to be essential 
sources of information. It is striking that actors that score higher on trust, scientists and general practitioners, did not score accordingly high here. They even scored a little lower than the polluters who were clearly perceived as being much less trustworthy.

When we compare these results with the outcomes of a question on actual experience with information sources with regard to environmental problems, we see more or less the same picture: media and governmental authorities, especially municipalities, scored relatively high.

Finally, we asked who should be responsible for solving environmental problems (Figure 4):

Figure 4 Actors responsible for solving environmental problems

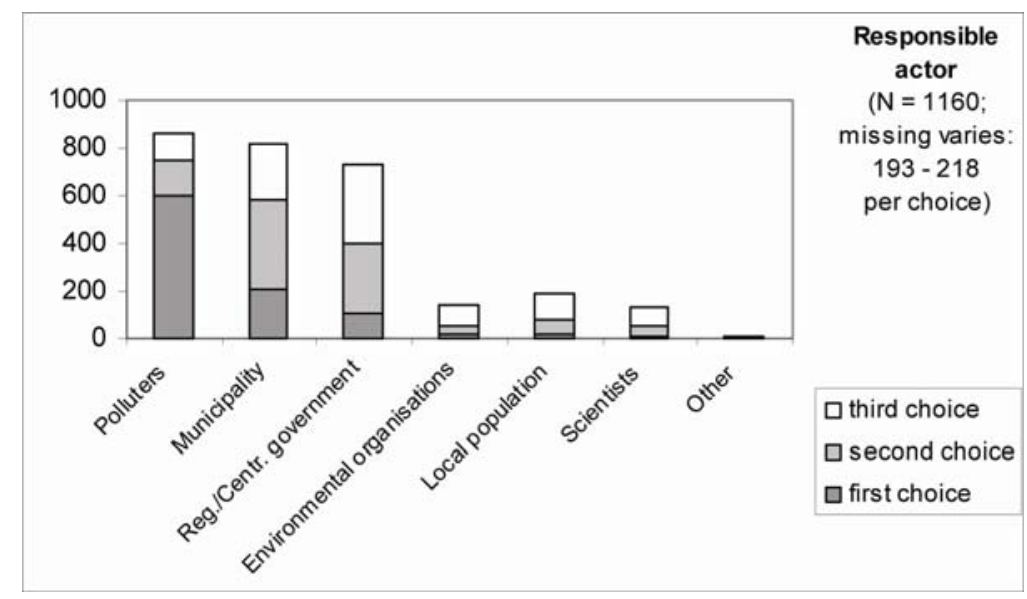

Clearly, respondents saw actors who cause problems as responsible for solving those problems in the first instance. Governmental authorities clearly played a second role. Whether the role of governments is linked mainly to steering the policy process or also to other responsibilities such as, costs, is not clear from these results.

We may conclude that trust in actors, trustworthiness of information and responsibility, are not necessarily 'in the same hands'. Experts such as scientists and general practitioners seem to be most trustworthy when it comes to information content with regard to environmental problems. For 4 out of 11 (pre-given) actors we see a statistically significant positive correlation with educational level and for two actors a statistically significant negative correlation with age. Preferred messengers for such information seem to be in first place governmental authorities, followed by the media. The least trustworthy actor, the polluter, is the first order responsible for solving these problems, followed though closely by governmental authorities. According to the respondents governmental authorities have to play a crucial role, but should perform better in order to gain more trust.

\subsection{Participation}

One of the strategies governmental institutions consider in order to gain (more) trust is involvement of the public in the policymaking process. However, participation is as complex a topic as trust. Here also, we can only focus on some aspects. 
We asked respondents what form of participation by local residents is preferred with regard to policies that aim to solve environmental problems (Figure 5):

Figure 5 Involvement of local residents in environmental policymaking

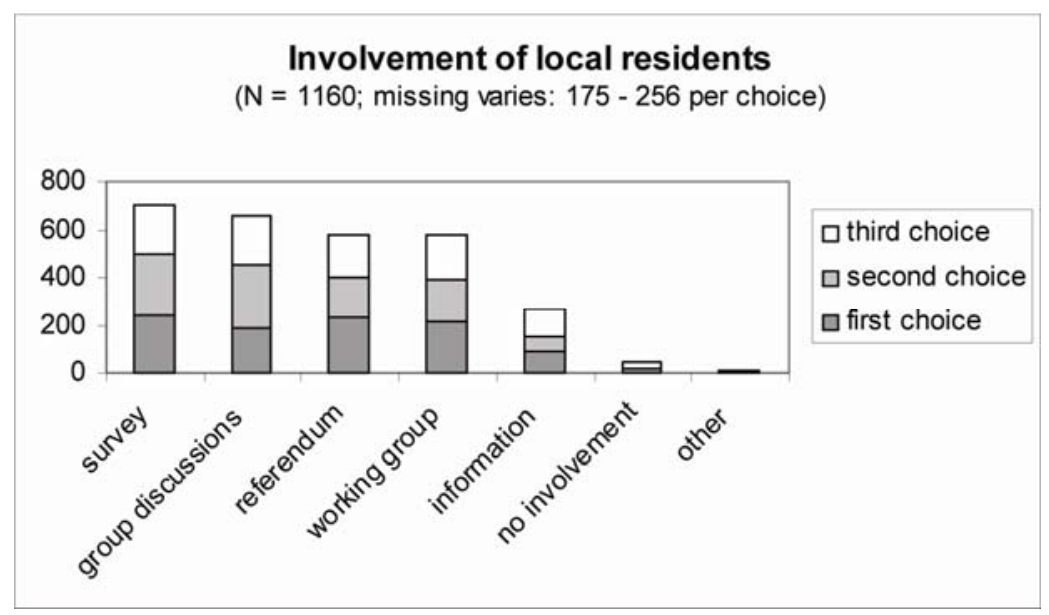

Clearly, most of the respondents preferred some form of active involvement. It is striking that interactive forms of participation (group discussions and working group) score equally high as non-interactive ones (survey and referendum). Statistical analysis on possible correlations between involvement and respondents' characteristics was only possible on the distinction between some form of involvement on the one hand and no involvement or merely supply of information on the other hand. We see a statistically significant positive relation with regard to preference for involvement and educational level ( $p=0.004$; Figure 6):

Figure 6 Involvement of local residents in environmental policymaking according to respondents with different educational levels

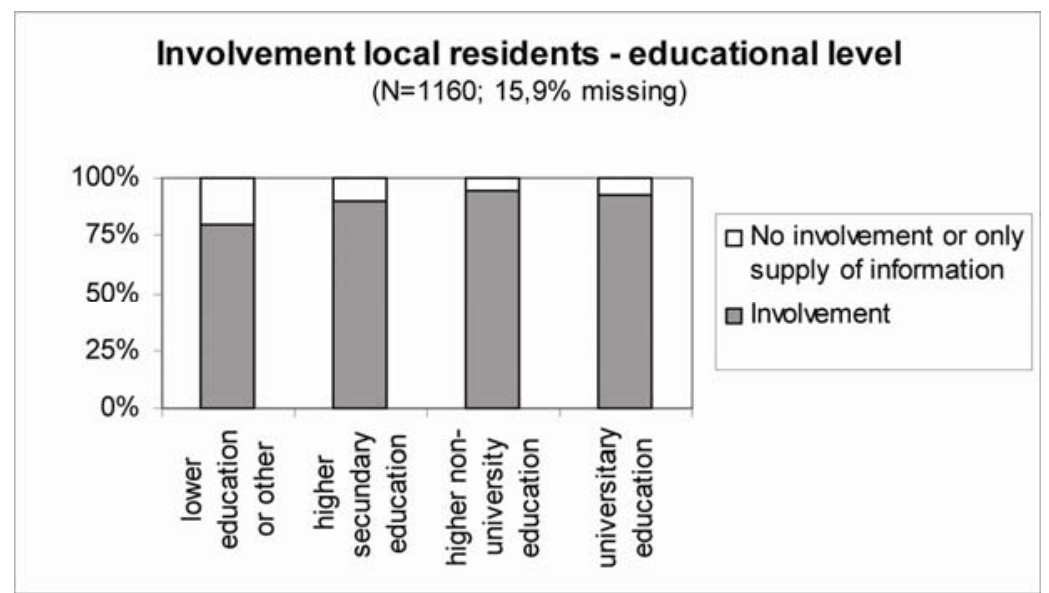


Even though the majority of respondents stressed the importance of participation in general, when asked on an individual level, enthusiasm seemed to be less obvious. The mothers of $72.1 \%$ indicate unwillingness to participate personally. Some respondents would be willing to participate under certain conditions. Most conditions focussed on the quality of the process, such as, influence and the constructive nature of the process, openness, objectivity and practical support.

When we look at the respondents' characteristics, we can find some interesting correlations with the willingness to participate. We do not find clear correlations with the study areas, but age $(p<0.0001)$ and educational level $(p<0.0001)$ clearly show a positive correlation. The same correlations were found with the perception of environmental problems. In conclusion: we see a link between the number of perceived environmental problems, the willingness to participate in problem solving, and a higher age and educational level. Also a positive relation was found between a preference for some form of involvement and educational level.

When governmental authorities decide to organise participation, they should take it seriously according to most respondents. This does not imply a shift of responsibilities to the public with regard to decision-making. The voice of the public should be taken seriously, but the authorities make the decisions. This corresponds with the way participation is looked at by the Centre of Expertise for Environment and Health in their work for the Flemish government.

\subsection{Policy}

At the end of the questionnaire, we asked in an open-ended question what should be improved with regard to environmental policy. Here, a wide range of answers came up, difficult to analyse statistically. Most topics that came up focus on any one of the three main issues: barriers to policy, practical solutions and measures, and quality of the policy process itself. One striking barrier concerned a necessary mentality shift. For most people, this was assessed to be rather hopeless. Another barrier referred to the 'window dressing' character of environmental policymaking, having therefore little practical impact. Finally, a noticeable barrier that was mentioned referred to little space for policymaking within the boundaries of the neo-liberal system.

Respondents put forward a great number of practical suggestions and measures. Some striking examples:

- free monitoring of children with regard to allergies

- less involvement from politics

- limiting residential areas

- Energy audits for every household.

Finally, some examples of quality improvement: accurateness, decisiveness, justice, control and monitoring activities, and the use of independent information.

\subsection{Perception research}

What did respondents think about perception research? Without their support, this kind of research is impossible. Again, we did not have the opportunity to go into detail within 
this subject. We limited ourselves to ask whether respondents would be willing to cooperate in further perception research, and if not, why. The respondents of $42.0 \%$ indicated willingness to participate in further perception research, while $49.0 \%$ indicated no willingness ( $9.0 \%$ missing). In contrast with conditions that came up with regard to participation, here the main reasons for absence of willingness to participate did not focus on quality (of the research) but on lack of time. Specific reasons put forward included: it is useless; it is the responsibility of experts; limited knowledge. This is contradictory to the items mentioned for conditional participation in policymaking.

When we look at individual characteristics, it is striking to see (again) a positive correlation between the willingness to cooperate and both age $(p=0.021)$ and educational level $(p<0.0001)$. Different study areas do not show much difference.

\section{Discussion and conclusions}

What is the importance of perception research to biomonitoring? We evaluate this from, respectively, the perspective of risk communication, knowledge integration, participation and perception management.

\subsection{Risk communication}

Some interesting messages for risk communication do arise from the results of the perception research. Investigating the health risks of environmental problems is the main aim of the biomonitoring. The 'unexpected' elevated levels of persistent chlorinated substances in samples from participants of rural areas were most conspicuously divergent from the perceptions of the respondents living there. It is wise to consider this when communication about biomonitoring results is undertaken in those areas.

Another informative result for communication is the fact that, in general, more than half of the respondents do not indicate any environmental problems. Apart from this being most specific for the study areas close to fruit orchards and the rural areas, this mainly holds for respondents relatively younger of age and with lower educational levels. The reasons for these last two factors are difficult to explain based on this research. We developed some hypotheses for further research: differences in vocabularies and levels of information with regard to the environment, coping behaviour, dependencies (e.g. economically), and perception of quality of life. Taking into account, these elements may improve the effectiveness of communication.

When we look at the indications with regard to sources of information on environmental problems, some lessons may be learned. Channels of communication do not necessarily coincide with sources of knowledge production: scientists and general practitioners appear to be most trustworthy, but are not seen as main channels for giving information. In addition, trust and responsibility do not necessarily coincide: the least trusted actor, the polluter, is seen as the first responsible for solving the problems. Clearly, for some obvious risk communication channels (media and government) it may be fruitful to invest in trustworthiness. For the Centre of Expertise for Environment and Health (scientists) when making use of such channels, the insights from perception research can be informative. 


\subsection{Knowledge integration}

Do the opportunities of this perception research (from a social scientific point of view) show in the practice of the medical and environmental experts? Does an interdisciplinary approach pay? Are the perceptions of the participants taken seriously? For now, this is only the case in a rather modest way. Of course, these processes take time and a lot of effort. The primary concern is the scientific responsibility of generating data and interpreting them scientifically. While trying to build bridges towards policy interpretation, the limitations of an exclusively scientific endeavour clearly showed: no scientist or group of scientists dared to claim to have the necessary and overarching knowledge to answer difficult questions (e.g. on medical and environmental policy priorities) when other than scientific factors had to be taken into account (economics, social preferences and feasibility of policy measures).

Together with the medical and environmental scientific experts and policymakers, the social scientists worked on the preparation of an action plan (Koppen, Keune and Casteleyn, 2005) for the interpretation, use and possible policy measures, with regard to the biomonitoring results. The social scientists especially focussed on the quality of the process. How to organise in a practical, relevant and efficient manner a high quality dialogue and cooperation between different actors, at different stages of the process: interpretation, further research, decision-making and policymaking. The main element the social scientists contributed was the development of a practice cycle: a practical procedure for assessment and decision-making. Part of this process is the composition of a jury that will judge relevant data and knowledge in order to give advice to the government. The jury will be made up of experts, stakeholders and (other) citizens. For the jury, we developed a multi-criteria analysis method. The action plan was agreed by both the Centre of Expertise for Environment and Health and policy representatives, and was adopted by the government.

One of the sources of information the Centre is considering to use for the detection of possible sources of pollution in the framework of this action-plan is the information gathered in the perception research. The environmental problems indicated by the respondents, as well as their willingness to cooperate further, may be proof of the value of the search for the additional knowledge needed to improve policymaking. In addition, information on trust and policymaking may contribute to take into account the social complexity of health and environment issues. These will be interesting steps towards inter- and transdisciplinary forms of knowledge integration and cooperation with regard to complex problems such as health and environment.

\subsection{Participation paradox and perception management}

The same group as discussed above with regard to risk communication (younger mothers with lower educational levels) seems to show less willingness to participate in policymaking and in perception research. We call this a participation paradox: the discrepancy between views on participation (participation is important) and willingness to act on them at a personal level. We cannot fully explain this on the basis of this research, even though the results give some clues for further research. We notice a correlation between the number of perceived environmental problems, the willingness to participate in problem solving, age and educational level. We do not know which factor or factors mainly trigger the willingness to participate: age, educational level or the 
perception of problems. Part of the explanation probably shows in conditions for participation brought forward by a small group of respondents. These conditions emphasise the importance of good process quality: inclusion of participants' views, objectivity and constructiveness. We may also have to conclude that taking people seriously in risk communication and management is important, but does not necessarily warrant willingness, on behalf of all groups, to take part in participatory processes.

Differentiation in perception management may be another result of perception research. The fact that most respondents who indicate environmental problems are also concerned about the health effects, but at the same time do not seem able to articulate specific health effects, may be of interest to perception management. When policies are for example aimed at reducing air pollution from traffic, information on health consequences may fill a gap in the awareness of people. In addition, differentiation in approaches towards different target groups (residential area, age, educational level and risk perception) may prove to be relevant.

\subsection{Conclusions}

Potentially this perception research is of added value for biomonitoring and policymaking on the basis of biomonitoring results. Though this value is not to be taken for granted and demands interest, openness and effort: without practical use and integration, it loses its meaning with regard to policy-relevant research such as the work of the Centre of Expertise for Environment and Health. The fruitful cooperation of different scientific disciplines within the Centre, and of the Centre with government representatives, is encouraging. First steps are made now and further steps will follow.

Future results on two other target groups of the biomonitoring (adolescents and adults between 50 and 65) will contribute to a more representative picture of perceptions in Flanders. Lessons learned in Flanders probably will be of inspiration to initiatives towards a biomonitoring approach at the level of the European Union: a pilot project to explore this has already started. Therefore, the perception research discussed in this paper can be evaluated as a successful experiment, with great potential for further development and use.

\section{Acknowledgements}

The study was commissioned, financed and steered by the Ministry of the Flemish Community (Department of Science, Department of Public Health and Department of Environment). The work was performed by the Centre of Expertise for Environment and Health. We gratefully acknowledge the collaboration of the 1,160 mothers of the newborn babies and the 25 Flemish maternities. Field work was done by trained nurses of the Antwerp Provincial Institute of Hygiene: Liliane Thys, Els Goossens, Nancy Maes, Ghis Meyssen, Babs Van Nesselrooij, coordinated by Dr. V. Nelen and E. Van de Mieroop. We are also grateful to the two anonymous reviewers for their insightful comments on the earlier versions of the manuscript. 


\section{References}

Ackaert, L. and Swyngedouw, M. (1998) 'Environmental consciousness and environmental behaviour of Flemish people, KUB, Brussel', Flanders Monitored: the Flemish Government and Population Research, (in Dutch), APS-survey (www.vlaanderen.be/statistiek).

Covello, V. (1991) 'Risk comparisons and risk communication: issues and problems in communicating health and environmental risks', in R.E. Kasperson and P.J.M. Stallen (Eds), Communicating Risks to the Public: International Perspectives, Dordrecht.

Centre of Expertise for Environment and Health. Available at: http://www.milieu-engezondheid.be/.

Drijver, M. and Woudenberg, F. (1999) 'Cluster management and the role of concerned communities and the media', European Journal of Epidemiology, Vol. 15, pp.863-869.

European Commission (2005) The Attitudes of European Citizens towards Environment, Eurobarometer. Available at: http://europa.eu.int/comm/public_opinion/archives/ ebs/ebs_217_en.pdf, [May 2005].

Keune, H. (2003) All is Quiet Next to the Polluting Factory? A Focus Group Study in Belgium, Paper presented in the Proceedings of VALDOR 2003 (VALues in Decisions on Risk), pp.483-491, June 9-13, 2003, Stockholm.

Keune, H., Mertens, R., Goorden, L. and Loots, I. (2002) Unrest in Moretusburg? Risk Communication with the Population Next to the Factory. Report on a Focus Group Consultation of the Population Next to a Polluting Factory in Belgium (In Dutch), Centre of Expertise for Environment and Health, Antwerp.

Keune, H., Nulens, G., Loots, I. and Goorden, L. (2005) What Do You Think about Environment and Health? Results Perception Questionnaire Biomonitoring Campaign New Born Babies 2002/2004, (in Dutch), Centre of Expertise for Environment and Health, Antwerp Belgium.

Koppen, G., Keune, H. and Casteleyn, L. (2005) Action Plan Biomonitoring Results; Centre of Expertise for Environment and Health (in Dutch).

Renn, O. and Levine, D. (1991) 'Credibility and trust in risk communication', in R.E. Kasperson and P.J.M. Stallen (Eds), Communicating Risks to the Public: International Perspectives. Amsterdam, The Netherlands: Kluwer.

Renn, O. and Rohrmann, B. (Eds) (2000) Cross-Cultural Risk Perception: A Survey of Empirical Studies. Dordrecht, The Netherlands: Kluwer.

Slovic, P. (1998) 'Perceived risk, trust and democracy', in R. Löfstedt and L. Frewer (Eds), Risk and Modern Society (pp.181-192), London.

Van Steertegem, M. (Ed.) (2005) Environmental Report Flanders: Themes, Mira-t 2005, Leuven, LannooCampus, Belgium (in Dutch).

Weale, A. (2000) 'Domestic politics and society-related variables', in A. Weale (Ed.), Environmental Governance in Europe (pp.235-294). Oxford, UK: UP.

Wynne, B. (1992) 'Risk and social learning', in S. Krimsky and D. Golding (Eds), Social Theories of Risk (pp.275-300). Westport, CT: Praeger Publishers.

Wynne, B. (1996) 'Misunderstood misunderstandings: social identities and public uptake of science', in A. Irwin and B. Wynne (Eds), Misunderstanding Science? The Public Reconstruction of Science and Technology (pp.19-46). Cambridge, UK: University Press.

\section{Notes}

${ }^{1}$ We used the Pearson $\chi^{2}$-square test ( $\alpha=0.05$, minimum of 50 respondents, maximum $20 \%$ of the frequencies with an expected count less than five, minimum expected count $\geq 1$ ).

${ }^{2}$ With regard to the research design, there are several differences between our research and the Eurobarometer poll. In the Eurobarometer research, individual face-to-face interviews are conducted (based on (uniform) questionnaires). The geographical 
coverage is much larger, since it is done in all European Union member countries. Moreover, the respondents to the Eurobarometer poll better represent the total population than does our research (only results with regard to mothers of newborn babies participating in the biomonitoring). When we look at content, one striking difference is that we focus on the environment and health, whereas the Eurobarometer research does not focus on this combination.

With regard to the question on trust in information sources, the approach also differs: whereas, in our research, in principle, every information source had to be scored, in this Eurobarometer poll respondents had to pick the three sources they trust most. 